\title{
Association between electronic cigarette use and tobacco cigarette smoking initiation in adolescents: A systematic review and meta-analysis
}

\section{Doireann O'Brien}

Health Research Board

Jean Long ( $\nabla$ jlong@hrb.ie)

Health Research Board, Dublin, Ireland https://orcid.org/0000-0002-0890-0797

Joan Quigley

Health Research Board

Caitriona Lee

Health Research Board

Anne McCarthy

Health Research Board

Paul Kavanagh

Health Services Executive

Research article

Keywords: Electronic cigarette use, Vaping, Tobacco cigarette initiation, Smoking, Adolescents

Posted Date: January 6th, 2021

DOI: https://doi.org/10.21203/rs.3.rs-59681/v3

License: (9) (i) This work is licensed under a Creative Commons Attribution 4.0 International License.

Read Full License

Version of Record: A version of this preprint was published at BMC Public Health on June 3rd, 2021. See the published version at https://doi.org/10.1186/s12889-021-10935-1. 


\section{Abstract}

Aim: This systematic review of prospective longitudinal primary studies aimed to explore whether electronic cigarette (e-cigarette) use by adolescents who had never smoked conventional tobacco cigarettes (tobacco cigarettes) at baseline was associated with subsequent initiation of tobacco cigarette smoking.

Methods: This study followed the principles of a systematic review and meta-analysis. A key word search identified peer-reviewed literature published between 1 January 2005 and 2 October 2019 from seven bibliographic databases and one search engine. Using predefined inclusion/exclusion criteria two authors independently screened abstracts, and subsequently, full text papers. Eligible papers were quality assessed by two authors. Data on population characteristics, exposure and outcome measures were extracted into an adapted Cochrane Data Extraction Form. Statistical analysis was preceded by a feasibility assessment, and included pairwise random effects meta-analyses, and sensitivity and subgroup analyses.

Findings: From an initial 6,619 studies, 14 unique primary studies in 21 papers were identified. The studies' populations ages ranged from 13 to 19 years at baseline and comprised teenagers based in Europe and North America. Nine of the 14 unique studies, with follow-up periods between 4 and 24 months, were eligible for inclusion in a meta-analysis of the association between ever use of e-cigarettes and subsequent initiation of tobacco cigarette use. Based on primary study adjusted odds ratios, our meta-analysis calculated a 4.06 (95\% confidence interval (Cl): 3.00-5.48) times higher odds of initiating tobacco cigarette smoking for those who had ever used e-cigarettes at baseline, although the odds ratio decreased marginally (to 3.71 times odds, $95 \% \mathrm{Cl}: 2.83-4$. 86) when only the four high-quality studies were analysed. The initial meta-analysis model had a high statistical heterogeneity, sensitivity analysis restricted to high-quality studies had moderate heterogeneity.

Conclusion: The systematic review found that e-cigarette use was associated with commencement of tobacco cigarette smoking among teenagers in Europe and North America, identifying an important public health harm. Given the widespread availability and use of e-cigarettes, this study further supports urgent action by policymakers to prevent their use by teenagers to reduce direct harms in this vulnerable population group, as well as to protect gains in reducing tobacco cigarette initiation.

\section{Background}

E-cigarettes were first sold into Europe in 2006 and into the United States of America (USA) in 2007 and as of 2017, 433 brands of e-cigarettes and 15,586 flavours had been documented [1]. E-cigarette usage has become more common since 2007. One study based on Eurobarometer surveys reported that 63 million (or 14.6\%) people residing in European Union member states aged 15 or older had ever used ecigarettes by 2017 (95\% confidence interval [Cl]: 59.9 million- 66.2 million), and 7.6 million (95\% Cl: 6.5 million-8.9 million) or $1.8 \%$ were current and regular e-cigarette users in 2017 [2]. Current (27.0\%) and 
former smokers (41.3\%) were more likely to be regular e-cigarette users than never smokers (12.8\%) [2]. In the USA, the self-reported use of e-cigarettes among adults in the month prior to the survey was $3.2 \%$ in 2018 , and use in young adults aged $18-24$ years was more than double at $7.6 \%$ in the same time period [3].

The 2011-2018 USA-based National Youth Tobacco Surveys reported that current e-cigarette use among high-school students, increased from $1.5 \%$ in 2011 to $20.8 \%$ in 2018 [4]. Surveys of 11-16-year-old children in the United Kingdom (UK) reported between $7 \%$ and $18 \%$ had ever used e-cigarettes, and between $67 \%$ and $92 \%$ of children who regularly smoked had ever used e-cigarettes in 2015-2016 [5]. The surveys' range for ever use of e-cigarettes among 11-16-year-olds who regularly smoked tobacco cigarettes was between $4 \%$ and $10 \%$, while the range for regular e-cigarette use among the same cohorts was between $0.1 \%$ and $0.5 \%$ [5]. The Health Behaviours in School Children study in Ireland found that $22 \%$ of $12-17$-year-old children had ever used e-cigarettes in 2018 , and $9 \%$ of $12-17$-year-olds had used e-cigarettes in the 30 days prior to the survey [6]. Perikleous et al. identified that e-cigarette use in the USA and Europe was associated with older teenagers, male adolescents, tobacco cigarette smokers, peer influence, daily smoking, and heavier smoking [7].

The emergence of e-cigarettes is a disruptive change challenging tobacco control globally [8-10], and countries are adopting different approaches to public health policy [11]. While the balance of harms and benefits of e-cigarettes for established smokers continue to be debated [12], their toxicological profile and the impact of nicotine on the developing adolescent brain make their use among children and young people especially concerning $[13,14]$.

In addition to the direct harm from e-cigarettes, one of the main concerns for this vulnerable group is potential for e-cigarette use to lead to tobacco cigarette use with its associated lifelong harms, and thereby undermining tobacco control initiatives. This is a critical area where evidence is required to inform public health policy [15].

Four published systematic reviews studied whether e-cigarette use to led to tobacco cigarette use. Soneji et al. synthesising seven primary studies reported that e-cigarette use is associated with an increased risk of future cigarette smoking initiation and current cigarette smoking in young people aged 14-30 years, even after adjusting for potential confounding by demographic, psychosocial, and behavioural risk factors [16]. Glasser et al. in an narrative analysis summarised that e-cigarette use is associated with subsequent smoking in young people [17]. Khouja et al. reported that there is strong evidence for an association between e-cigarette use and subsequently cigarette smoking in their meta-analysis of baseline non-smokers aged up to 30 years (OR: 4.59, 95\% Cl: 3.60 to 5.85, I² 88\%)[18]. Aladeokin and Haighton, in a three-study meta-analysis, demonstrated that UK-based adolescents who use e-cigarettes were six times more likely to smoke tobacco cigarettes. Only one of the three systematic reviews focused exclusively on adolescents, and this review included UK-based adolescents only [19]. 
Given the significance of teenage years in establishing future smoking behaviour internationally [20], the aim of the systematic review was to build on existing work by determining if e-cigarette use by adolescents who never smoked tobacco cigarettes at baseline was associated with subsequent initiation of cigarette smoking through a meta-analysis of the longitudinal prospective studies. The final included studies represent a wider population from Europe and North America than in Aladeokin and Haighton [19]. Our review includes a larger number of studies and participants and so provide a more stable and generalisable estimate.

\section{Methods}

This study followed the principles of a systematic review and meta-analysis.

\section{Literature search strategy and inclusion-exclusion criteria}

Our information specialist completed a structured and robust search of seven databases and one search engine for peer-reviewed literature on e-cigarettes published between 1 January 2005 and 15 April 2019. The sources searched were Ovid MEDLINE (Appendix 1), Cochrane Library, Ovid PsycINFO, Elsevier Embase, PROSPERO, LILACS, CORE.ac.uk, and Google Scholar. The searches were updated twice, using Ovid MEDLINE, during the review period with an end date 2 October 2019. Our keywords were based on variations of English terms for e-cigarette, for example, e-cig*, e-liquid, vape, vaping, cigalike, electronic nicotine delivery system (ENDS), and electronic non-nicotine delivery. Non-English terms for these concepts were also included, for example, e-sigaret*, E-zigarette, and e-papieros. Using predefined inclusion/exclusion criteria(Table 1), two independent authors completed three rounds of screening. We completed backward citation searching on all studies included in the review. Our PRISMA diagram is presented in Appendix 2. This systematic review followed the Centre for Reviews and Dissemination's guidance for undertaking reviews in health care [21].

\section{Table 1 Population, intervention, comparator and outcome inclusion criteria for review question}

\section{Element Description}

Adolescents who never smoked tobacco cigarettes at baseline. The age of

Population the included population was between 13 and 19 years at baseline. The could be living in any country around the Globe.

Exposure Any e-cigarette vaping at baseline or in the past

Comparators Non-electronic cigarette user

Outcomes Initiation of tobacco cigarette smoking at follow-up

Study design

Longitudinal cohort studies

Search dates

2005-2019 
Two researchers independently assessed the quality of the included studies using the National Heart, Lung, and Blood Institute's (NHLBI's) 14-item quality assessment tool for observational cohort and crosssectional studies (Appendix 3) [22]. One researcher extracted key population, exposure, and outcome data from the included papers into an adapted Cochrane Data Extraction Form [23] and these extracted data were validated by another researcher.

\section{Statistical analyses}

A meta-analysis feasibility assessment was completed including the 14 studies in order to decide whether to complete meta-analysis and to decide the more appropriate meta-analysis method [2426]. The feasibility analysis considered the studies' variation in outcome, exposure, unit of measurement, and length of time to follow-up. A pairwise random effects meta-analyses using the primary studies adjusted odds ratios, to compare outcomes of two-armed longitudinal studies exposures, was completed for the outcome 'initiated tobacco cigarette smoking' during the study follow-up period [27-29]. The $I^{2}$ statistic describes the percentage of the variability in treatment effects that is due to statistical heterogeneity rather than sampling error (chance). We completed two sensitivity analyses: one including high-quality studies only and another including studies that controlled for three domains of confounding (demographic, interpersonal, intrapersonal). Sub-group analyses were also conducted by year of data collection (baseline data collection pre 2014 compared to baseline data collection 2014 to date), geographical region (North America versus Europe) and length of follow-up (less than 12 months compared to 12 months or more). A level of evidence [30] and a GRADE recommendation [31] were assigned to included data. The methods for this paper are described in detail elsewhere [32].

\section{Results}

\section{Study and population characteristics}

The searches retrieved 6,619 studies (6,510 papers from the initial searches, plus 109 papers from supplemental searches). Two researchers selected 21 papers for inclusion in the study (Appendix 2); comprising 14 unique longitudinal prospective studies (Appendices $4-8$ ). The data in the primary studies were collected between 2013 and 2016 and their longitudinal follow-up periods ranged from 4 months to 2.5 years. Only one study had two follow-up time points [33]. Fifteen primary papers were completed using North American populations [33-47] and six primary papers were based on European populations [48-53]. The studies' populations ages ranged from 13 to 19 years at baseline. The included studies had a range of research questions related to e-cigarette use; 17 enquired about ever use of ecigarettes [33, 36-40, 42, 44-53], and 4 queried current e-cigarette use in the past 30 days [35, 40, 43, 44]. Data on e-cigarette type, generation or liquid were not asked about in any study. The papers assessed tobacco cigarette smoking during follow-up as an outcome variable: 18 papers studied ever use of tobacco cigarettes between baseline and follow-up [33, 35, 37-52], and 4 queried past 30-day use of tobacco cigarettes $[39,40,42,44]$. The publications completing regression analysis included potential 
confounding variables as covariates in their regression model, ranging from the inclusion of 3 variables to the inclusion of 17. Based on previous research, we grouped the covariates into three groups: demographic (e.g. age, gender, ethnicity, family affluence), interpersonal (e.g. number of friends/family members that smoke) or intrapersonal (e.g. such impulsivity, sensation seeking, rebellion) [17]. One paper [36] collected data on variables from a single domain, while eight papers $[35,38,43,46,47,50,51,53]$ had variables representing two domains, and ten papers $[33,34,39,40,42,44,45,48,49,52]$ had variables from all three domains.

\section{Quality assessment}

Overall, using the NHLBI quality assessment tool [22], we considered four studies to be high-quality[39, $44,47,52$ ] as they had a representative and clearly defined sample with a participation rate of more than $50 \%$, a loss to follow-up rate of $20 \%$ or less, and a sample size justification or variance calculation for the main outcomes (Appendix 3). The remaining studies in the meta-analysis were judged to be moderate quality and tended to have higher loss to follow up or lower participation rates.

\section{Feasibility assessment}

In order to ascertain whether a meta-analysis was appropriate and which studies should be included, a feasibility analysis was conducted, assessing if the primary study authors employed the same method of analysis considering outcome, exposure, unit of measurement, and length of time to follow-up (Appendix 9). Based on these criteria, nine studies with 16,808 participants were considered eligible for metaanalysis of ever using e-cigarette at baseline and smoked tobacco cigarettes at any time during the follow-up period (Figure 1), while three studies of past-30-day e-cigarette use at baseline and smoked tobacco cigarettes at any time during the follow-up period were eligible.

\section{Ever e-cigarette use at baseline and subsequent cigarette smoking at follow-up}

Our ever e-cigarette-use meta-analysis was based on the primary study adjusted odds ratios and calculated a combined 4.06 (95\% Cl: $3.00-5.48, \mathrm{I}^{2} 68 \%$ ) times higher odds of initiating smoking tobacco cigarettes for those who had ever used e-cigarettes at baseline, although this combined odds ratio decreased marginally to 3.71 times ( $95 \% \mathrm{Cl}$ : 2.83-4. 86, $\mathrm{I}^{2} 35 \%$ ) when only the four high-quality studies [39, $44,47,52]$ were analysed in a sensitivity analysis(Appendix 10). The initial meta-analysis model had a high statistical heterogeneity, sensitivity analysis restricted to high-quality studies had moderate statistical heterogeneity.

Figure 1 here

One additional sensitivity analysis was completed on six studies $[33,39,44,48,49,52]$ that controlled for the three domains of covariates - that is, demographic, interpersonal, and intrapersonal factors. The results of this sensitivity analysis (OR: $3.82 ; 95 \% \mathrm{Cl}$ : 2.66-5.48; $\mathrm{I}^{2} 69 \%$ ) were like the results for the highquality studies sensitivity analysis, but the level of heterogeneity remained high (Appendix 10). 
Three subgroup analysis were done (Appendix 10). The first compared studies which collected data pre2014 [33, 39, 47] with those which collected their initial data from 2014 onwards [38, 44, 48, 49, 51, 52], due to the rise in e-cigarette use that was noticed around this time [54]. The combined OR for studies which collected data from 2014 onwards increased substantially (pre-2014 AOR: 2.81, 95\%Cl: 2.45-3.72 $\mathrm{I}^{2} 78 \%$ ); compared to 2014 onwards (5.16,95\% Cl: 3.69-7.21 I 38\%). However, the confidence intervals overlap indicating that they are not statistically significantly different.

The second subgroup analysis compared the length of time to follow-up, as studies included in the analyses had follow-up periods which ranged from 4 months to 2 years. However, as only two studies had follow-up periods of less than 1 year $[49,51]$ including one study which had a very small sample size, the meta-analysis for this subgroup did not provide useable results.

Finally, considering the significance of the geographical, regulatory, and cultural context of these studies, we compared European studies with those from the USA. The combined OR was higher in the European studies (OR: $6.22,95 \% \mathrm{Cl}$ : $3.73-10.38 \mathrm{I}^{2} 54 \%$ ) [48, 49, 51, 52] compared with the USA studies (OR: 3.18 , $\left.95 \% \mathrm{Cl}: 2.26-4.47 \mathrm{I}^{2} 65 \%\right)[33,38,39,44,47]$. However, the confidence intervals overlap indicating that they are not statistically significantly different.

\section{Past-30-day e-cigarette use at baseline and subsequent cigarette smoking at follow-up}

Four studies examined the impact of past-30-day e-cigarette use at baseline and subsequent cigarette smoking at follow-up $[35,40,43,44]$. One of the four studies was excluded following feasibility analysis prior to meta-analysis. A meta-analysis was completed using the remaining three primary studies adjusted odds ratios (Appendix 10) and included 30,018 participants. The meta-analysis identified a significant positive association between past-30-day e-cigarette use at baseline and subsequent cigarette smoking initiation at follow-up (OR: 2.14; 95\% Cl: 1.75-2.62; $\left.\right|^{2}$ 0\%) (Figure 2) [35, 40, 44].

Figure 2 here

\section{Level and certainty of evidence}

We assigned a level of evidence of 3 using British Medical Journal guidelines [30], as this is a systematic review of cohort studies, some of which had high loss to follow-up and/or very small sample sizes. With respect to certainty of evidence [31] and taking account of study design and statistical heterogeneity, we have moderate confidence that the true effect is likely to be close to the estimated effect for initiating smoking at follow-up for those who had ever used e-cigarettes at baseline.

\section{Discussion}

\section{Main findings}

We calculated a more precise and generalisable estimate of the odds of tobacco cigarette smoking initiation following ever use of e-cigarettes in adolescents in Europe and North America. We identify a 
four-fold increased likelihood between e-cigarettes use and initiating smoking tobacco cigarettes in adolescents in a combined analysis of nine cohort studies conducted with follow-up periods between 4 and 24 months. Sensitivity and subgroup analysis support the relationship between ever using ecigarettes and initiating smoking tobacco cigarettes. Six studies controlled for confounding under three domains (demographic, interpersonal, and intrapersonal) while examining the association between using e-cigarettes and initiating smoking tobacco cigarettes, and had a similar, significant estimate of effect in meta-analysis. The four high-quality studies also had a similar estimate of effect but lower statistical heterogeneity. The remainder of the studies were judged to be moderate quality because of their small sample sizes and/or high loss to follow-up.

The longitudinal prospective study design used to evaluate the relationship between e-cigarette use and initiation of tobacco cigarette smoking permits researchers to start the process of establishing a causal relationship. Across all primary studies included in the meta-analysis, the adjusted odds ratios and confidence intervals are consistent, and the strength of association is statistically significant. Moreover, the use of e-cigarettes which occurred before initiating smoking, fulfils the criteria for a temporal relationship. Finally, two studies in this review have illustrated a dose-response relationship. We have moderate confidence that the true effect is probably close to the estimated effect for initiating smoking at follow-up for those who had ever used e-cigarettes at baseline, as all meta-analyses indicate that there is a significant positive association between using e-cigarettes at baseline and smoking tobacco cigarettes at follow-up, and this effect size is quite large; the findings are statistically significant, consistent, and the exposure occurred before the outcome. We also found a significant two-fold positive association between past-30-day e-cigarette use at baseline and subsequent cigarette smoking initiation at follow-up. This is a more restricted measure of exposure with a shorter duration during which the non-user can take up vaping, but shows the same positive association among smoking initiators demonstrating that ecigarette vaping in non-smokers in the 30 days prior to data collection increases the odds of taking up tobacco cigarette smoking.

\section{Strengths and limitations}

Given that there were 433 brands of e-cigarettes and 15,586 flavours documented by 2017[1], the primary limitation of the research in this area is the heterogeneity of the exposure (e-cigarette) in terms of generation, product type, e-liquid and its nicotine content. The included studies did not ask specific questions about the e-cigarette used, and only two $[51,53]$ of the 21 studies measured the differences between nicotine and non-nicotine e-cigarettes. This is relevant as e-cigarettes industry is developing new products rapidly.

None of the cohort studies did biochemical verification of outcomes as they relied on the tried and tested questions about ever use, recent or last year use, and current or last 30 days use and these measures are accepted the world over for surveying the use of tobacco products, licit drugs, and illicit drugs [55]. The most common measure of both e-cigarette and cigarette use was 'ever use' of either product, an indicator which has been critiqued by researchers [56], as it did not observe whether the teenagers used the product 
once in their young life, or if they used it regularly. 'Past-30-day use' has gotten the same censure. However, the use of these indicators has been justified, with a recent study by Birge et al. finding that over two-thirds of smokers who ever consumed a single puff of a tobacco cigarette during adolescence became, for a time, regular smokers [57].

\section{Comparison with previous systematic reviews}

The results of this up-to-date and comprehensive systematic review are in line with three published metaanalyses[16] [19] [18], that also found an association between initiation of e-cigarette use and subsequent smoking. However, this systematic review consolidates and extends the evidence base for public health policy because it used nine studies concentrating on adolescents who resided in a wider geographical region, and the analysis also took account of quality and confounding. The World Health Organization, based on the U.S. National Academies of Sciences, Engineering, and Medicine's systematic narrative review, reported that there is moderate evidence that young never smokers who experiment with e-cigarettes are at least two times more likely to experiment with smoking later, which is lower than, but in line with our findings [58]. The meta-analyses presented in this paper, however, includes newer studies not analysed in the U.S. Academies of Sciences review.

\section{Future research}

An important question still to be answered relates to the principal catalysts in the relationship between ecigarette and tobacco cigarette use. Researchers have tried to clarify the move from using e-cigarettes to smoking tobacco cigarettes through three theories which are the gateway theory [59], the common liability theory [60-63], and the catalyst model [64]. Future research is required to test these three theories (or elements thereof) in more depth.

In terms of the most appropriate study design for assessing causality, Etter recommended large longitudinal epidemiological studies which measure smoking onset, control for confounders, and include a propensity score measure of liability to smoking [56]. In addition to this, we propose exploring the phenomenon using explorative and in-depth quantitative and qualitative methods to understand the thinking and behaviour of adolescents who use e-cigarettes and subsequently move to tobacco cigarettes or use both, so as to provide enhanced interventions to prevent these practices.

Most research has taken place in Europe and North America: there is a need for research for cross-country research including low- and middle-income countries where the burden of tobacco cigarette use is the highest.

No study provided information on e-cigarette type, generation or liquid. It is important to note that ecigarettes and their e-liquids were not a standard commodity or exposure but an umbrella term for a device that delivers nicotine and other products including flavourings [65]. Independent longitudinal research into e-cigarette devices and their liquids over several years is essential to identify and limit their long-term effects on human health. 
Given over six million deaths attributable to smoking worldwide each year[66], tackling tobacco use continues to be a global health priority, with countries at different stages in controlling the epidemic and some high-income countries signalling intent to transition from tobacco control to tobacco endgame [67, 68]. E-cigarettes are a disruptive innovation raising new questions for health policymakers [8-10]. Debate on the harms and potential benefits of e-cigarettes has dominated tobacco control discourse [69], and became even more charged with the emergence of e-cigarette, or vaping, product use-associated lung injury (EVALI) in 2019 [70]. Two viewpoints, which often appear conflicting emerge: a harm minimisation approach is proposed to leverage a potentially favourable balance of harms and benefits for people who smoke so as to mitigate the overwhelmingly bleak odds they face from their use of combustible tobacco products [71], while a precautionary approach is advised given the many unknowns regarding e-cigarette use, evidence of tobacco industry interference, and previous false dawns of 'safer' tobacco products [72].

To find a way forward through these competing viewpoints, policymakers must carefully appraise evidence on risk, benefits, and trade-offs while understanding the framing and wider context of the debate [15, 73-75]. The U.S. National Academies of Sciences, Engineering, and Medicine, were commissioned by the Food and Drugs Administration to systematically review scientific evidence to inform e-cigarette policy [76], while in Europe the Scientific Committee on Health, Environmental and Emerging Risks has been mandated to assist the European Commission in assessing the most recent scientific and technical information on e-cigarettes as part of its review of the Tobacco Products Directive 2014/40/EU [77]. Similarly, the study presented in this paper was conducted as part of broader programme of evidence reviews to inform and support public health policy in Ireland, which included mapping of the harms and benefits of e-cigarettes (and their e-liquids) [65] and a systematic review of e-cigarettes role in smoking cessation [78]. We found that e-cigarettes (and their e-liquids) lead to acute harms such as poisoning, lung injury, and burns and blast injuries, a finding aligned with six other systematic reviews [58, 76, 79-82], and highlighted a need for continuing study using robust methods to measure the long-term health impacts of their use as these are not yet known. We also found that approved and regulated nicotine replacement therapies with established safety profiles were as effective as e-cigarettes in helping smokers quit [78].

Against a backdrop of often clashing harm reduction and precautionary viewpoints on e-cigarettes, mobilising evidence, while necessary, is difficult for policymakers This difficulty is exacerbated when the relationship between evidence and policy is seen as a linear "know-do-gap", instead of recognising the "muddling through" of the policy process [83]. The harms, benefits and trade-offs to be considered by policymakers in the area of e-cigarettes are likely to be different across population groups and require a finely balanced blend of policies which are precautionary for vulnerable groups while retaining potential prospect of harm reduction for some highest-risk groups not amenable to other risk management measures. 
In the case of any non-smokers, be they children, young people, or adults, e-cigarettes offer no benefits and present potential for harm from nicotine dependence and exposure to known toxins. The mandate for policy action to maximise protection of children and adolescents is further strengthened by the systematic review presented in this paper, in which we found that e-cigarettes were associated with initiation of tobacco cigarette smoking among adolescents. This is a identifying an important public health harm which undermines hard-won progress in tobacco control, that have been largely delivered through preventing smoking initiation in youth. Other researchers have noted that two-thirds of these adolescents may go on to smoke tobacco cigarettes for a period [57]. Children and adolescents should be offered the same protection from e-cigarettes as conventional tobacco cigarettes through a well-enforced regulatory regime of measures including age restriction on purchase, control of availability through licensing outlets, limits to product visibility and attractiveness, and appropriate pricing through taxation. Before exploring the potential for harm reduction for highest-risk groups and those for whom regulated pharmaceutical interventions do not work, policymakers should assure protection of children, adolescents and never smokers as their next evidence-informed, precautionary step through this complex and challenging policy process, so as to reduce direct harms from e-cigarettes in these vulnerable populations and to protect gains in reducing tobacco use initiation.

\section{Conclusion}

The systematic review and meta-analysis found that e-cigarette use was associated with initiation of tobacco cigarette smoking among teenagers in Europe and North America, identifying an important public health harm. The meta-analysis presents a more precise and generalisable estimate of the odds of tobacco cigarette smoking initiation following ever use of e-cigarettes in teenagers. Given the widespread availability and use of e-cigarettes, this study further supports urgent action by policymakers to prevent their use by adolescents to reduce direct harms in this vulnerable population group as well as to protect gains in reducing tobacco cigarette initiation.

\section{Abbreviations}

AOR: adjusted odds ratio; $\mathrm{Cl}$ : confidence interval; e-cigarette: electronic cigarette; e-liquid: electronic liquid for e-cigarette; EVALI: e-cigarette, or vaping, product use-associated lung injury; NHLBI: National Heart, Lung, and Blood Institute; OR: odds ratio; UK: United Kingdom; USA: United States of America

\section{Declarations}

\section{Acknowledgements}

We would like to thank the Department of Health in Ireland for setting this interesting research question.

\section{Authors' contributions}


DOB conceptualized the research question and developed the search, screening and analysis plan jointly with $\mathrm{AMCC}, \mathrm{CL}, \mathrm{JQ}$ and JL. DOB, AMCC and CL screened the literature. DOB completed data extraction with $\mathrm{JL}$ as second reviewer and both $\mathrm{DOB}$ and $\mathrm{JL}$ completed the quality assessment. DOB, JQ and $\mathrm{JL}$ analyzed the data. JL and $\mathrm{DOB}$ drafted the manuscript, and $\mathrm{PK}, \mathrm{AMCC}$, JQ and $\mathrm{CL}$ read and contributed to revising the manuscript. All authors read and approved the final manuscript.

\section{Funding}

The systematic review was funded as part of the routine work of the Health Research Board.

\section{Availability of data and materials}

The primary research papers are available through bibliographic databases. The PRISMA flow chart, quality assessment sheet, and data extraction sheet is provided as part of the supplementary materials.

\section{Ethics approval and consent to participate}

As all data is published in primary papers, ethics approval for this analysis was not required. Consent for publication

Not applicable.

\section{Competing interests}

The authors declare that they have no competing interests.

\section{Author details}

*Health Research Board, Grattan House, 67-72 Lower Mount Street, Dublin 2, D02 H638, Ireland, e doireann1910@gmail.com; jlong@hrb.ie; jquigley@hrb.ie; clee@hrb.ie; amccarthy@hrb.ie;

¥Health Intelligence, Strategic Planning and Transformation, Health Service Executive, 4th Floor, Jervis House, Jervis Street, Dublin 1, D01 W596, Ireland. e paul.kavanagh@hse.ie

\section{References}

1. Hsu G, Sun JY, Zhu S-H. Evolution of electronic cigarette brands from 2013-2014 to 2016-2017: Analysis of brand websites. J Med Internet Res 2018, 20(3):e80; doi: 10.2196/jmir.8550.

2. Laverty AA, Filippidis FT, Vardavas $\mathrm{Cl}$. Patterns, trends and determinants of e-cigarette use in 28 European Union Member States 2014-2017. Prev Med 2018, 116:13-18; doi: 10.1016/j.ypmed.2018.08.028.

3. Dai H, Leventhal AM. Prevalence of e-cigarette use among adults in the United States, 2014-2018. JAMA 2019, 322(18):1824-1827; doi: 10.1001/jama.2019.15331. 
4. Cullen KA, Ambrose BK, Gentzke AS, Apelberg BJ, Jamal A, King BA. Notes from the field: Use of electronic cigarettes and any tobacco product among middle and high school students - United States, 2011-2018. MMWR Morb Mortal Wkly Rep 2018, 67:1276-1277; doi:

10.15585/mmwr.mm6745a5.

5. Bauld L, MacKintosh AM, Eastwood B, Ford A, Moore G, Dockrell M, Arnott D, Cheeseman H, McNeill A. Young people's use of e-cigarettes across the United Kingdom: Findings from five surveys 20152017. Int J Environ Res Public Health 2017, 14(9):E973; doi: 10.3390/ijerph14090973.

6. Költő A, Gavin A, Molcho M, Kelly C, Walker L, Nic Gabhainn S. The Irish Health Behaviour in Schoolaged Children (HBSC) Study 2018. Dublin, Ireland: Department of Health \& Galway Health Promotion Research Centre, National University of Ireland, Galway; 2020. Available from: https://doi.org/10.13025/zvwm-rp65

7. Perikleous EP, Steiropoulos P, Paraskakis E, Constantinidis TC, Nena E. E-cigarette use among adolescents: An overview of the literature and future perspectives. Front Public Health 2018, 6:86; doi: 10.3389/fpubh.2018.00086.

8. Stimson GV, Thom B, Costall P. Disruptive innovations: The rise of the electronic cigarette. Int J Drug Policy 2014, 25(4):653-655; doi: 10.1016/j.drugpo.2014.05.003.

9. Abrams DB. Promise and peril of e-cigarettes: can disruptive technology make cigarettes obsolete? JAMA 2014, 311:135-136; doi: 10.1001/jama.2013.285347.

10. Fagerstrom K, Etter JF, Unger JB. E-cigarettes: A disruptive technology that revolutionizes our field? Nicotine Tob Res 2015, 17(2):125-126; doi: 10.1093/ntr/ntu240.

11. Kennedy RD, Awopegba A, De León E, Cohen JE. Global approaches to regulating electronic cigarettes. Tob Control 2017, 26(4):440-445; doi: 10.1136/tobaccocontrol-2016-053179.

12. Green LW, Fielding JE, Brownson RC. The debate about electronic cigarettes: Harm minimization or the precautionary principle. Annu Rev Public Health 2018, 39:189-191; doi: 10.1146/annurevpublhealth-102417-124810.

13. Goniewicz ML, Knysak J, Gawron M, Kosmider L, Sobczak A, Kurek J, Prokopowicz A, JablonskaCzapla M, Rosik-Dulewska C, Havel C et al. Levels of selected carcinogens and toxicants in vapour from electronic cigarettes. Tob Contro/ 2014, 23(2):133-139; doi: 10.1136/tobaccocontrol-2012050859 .

14. Goriounova NA, Mansvelder HD. Short- and long-term consequences of nicotine exposure during adolescence for prefrontal cortex neuronal network function. Cold Spring Harb Perspect Med 2012, 2(12):a012120; doi: 10.1101/cshperspect.a012120.

15. Newton JN, Dockrell M, Marczylo T. Making sense of the latest evidence on electronic cigarettes. Lancet 2018, 391(10121):639-642; doi: 10.1016/S0140-6736(18)30202-2.

16. Soneji S, Barrington-Trimis JL, Wills TA, Leventhal AM, Unger JB, Gibson LA, Yang J, Primack BA, Andrews JA, Miech RA et al. Association between initial use of ecigarettes and subsequent cigarette smoking among adolescents and young adults: A systematic review and meta-analysis. JAMA Pediatr 2017, 171(8):788-797; doi: 10.1001/jamapediatrics.2017.1488. 
17. Glasser A, Abudayyeh H, Cantrell J, Niaura R. Patterns of e-cigarette use among youth and young adults: Review of the impact of e-cigarettes on cigarette smoking. Nicotine Tob Res 2019, 21(10):1320-1330; doi: 10.1093/ntr/nty103.

18. Khouja JN, Suddell SF, Peters SE, Taylor AE, Munafò MR. Is ecigarette use in non-smoking young adults associated with later smoking? A systematic review and meta-analysis. Tob Control 2020:tobaccocontrol-2019-055433; doi: 10.1136/tobaccocontrol-2019-055433.

19. Aladeokin A, Haighton C. Is adolescent e-cigarette use associated with smoking in the United Kingdom? A systematic review with meta-analysis. Tob Prev Cessat 2019, 5(April):15; doi: $10.18332 / \mathrm{tpc} / 108553$.

20. Everett SA, Warren CW, Sharp D, Kann L, Husten CG, Crossett LS. Initiation of cigarette smoking and subsequent smoking behavior among U.S. high school students. Prev Med 1999, 29(5):327-333; doi: 10.1006/pmed.1999.0560.

21. Centre for Reviews and Dissemination, Akers J. Systematic reviews : CRD's guidance for undertaking reviews in health care. York: CRD, University of York; 2009: 281pp. Available from:

https://www.york.ac.uk/crd/guidance/

22. National Heart, Lung, and Blood Institute,. Study quality assessment tools. Quality assessment of controlled intervention studies. Bethesda, Maryland.: National Heart, Lung, and Blood Institute, National Institutes of Health,; [No date]. Available from: https://www.nhlbi.nih.gov/healthtopics/study-quality-assessment-tools

23. Cochrane Effective Practice and Organisation of Care (EPOC). Data collection form. EPOC resources for review authors. Cochrane Effective Practice and Organisation of Care (EPOC); 2017. Available from: https://epoc.cochrane.org/sites/epoc.cochrane.org/files/public/uploads/Resources-forauthors2017/good_practice_data_extraction_form.doc

24. Quigley JM, Woods B, Thompson J, Bryden PA, Scott DA. PRM209 - Confronting heterogeneity: Using systematic review effectively for meta-analysis. Value Health 2013, 16(7):A612; doi:

10.1016/j.jval.2013.08.1763.

25. McKenzie JE, Brennan SE, Ryan RE, Thomson HJ, Johnston RV. Summarizing study characteristics and preparing for synthesis. In: Cochrane Handbook for Systematic Reviews of Interventions. edn.; 2019: 229-240.

26. Cope S, Zhang J, Saletan S, Smiechowski B, Jansen JP, Schmid P. A process for assessing the feasibility of a network meta-analysis: a case study of everolimus in combination with hormonal therapy versus chemotherapy for advanced breast cancer. BMC Med 2014, 12:93; doi: 10.1186/17417015-12-93.

27. General package for meta-analysis [program] [https://github.com/guido-s/meta]

28. Meta-analysis with R. [http://www.imbi.uni-freiburg.de/lehre/lehrbuecher/meta-analysis-with-r]

29. Deeks JJ, Higgins JPT, Altman DG. Chapter 10: Analysing data and undertaking meta-analyses Cochrane Handbook for Systematic Reviews of Interventions version 60 (updated July 2019) Edited 
by Higgins JPTe, Thomas Je, Chandler Je, Cumpston Me, Li Te, Page MJe, Welch VAe: Cochrane Collaboration; 2019. Available from: https://training.cochrane.org/handbook/current/chapter-10

30. Murad MH, Asi N, Alsawas M, F. A. New evidence pyramid. Evid Based Med 2016, 21(4):125-127; doi: 10.1136/ebmed-2016-110401.

31. Schünemann He, Brożek Je, Guyatt Ge, Oxman Ae. GRADE handbook for grading quality of evidence and strength of recommendations (Updated October 2013). GRADE Working Group; 2013. Available from: https://gdt.gradepro.org/app/handbook/handbook.html\#h.u1371quprl84

32. O'Brien D, Long J, Lee C, McCarthy A, Quigley JM. Electronic cigarette use and tobacco cigarette smoking initiation in adolescents. An evidence review Dublin: Health Research Board;; 2020. Available from: https://www.hrb.ie/publications/publication/electronic-cigarette-use-and-tobaccocigarette-smoking-initiation-in-adolescents-an-evidence-review/returnPage/1/

33. Leventhal AM, Strong DR, Kirkpatrick MG, Unger JB, Sussman S, Riggs NR, Stone MD, Khoddam R, Samet JM, Audrain-McGovern J. Association of electronic cigarette use with initiation of combustible tobacco product smoking in early adolescence. JAMA 2015, 314(7):700-707; doi:

10.1001/jama.2015.8950.

34. Aleyan S, Cole A, Qian W, Leatherdale ST. Risky business: A longitudinal study examining cigarette smoking initiation among susceptible and non-susceptible ecigarette users in Canada. BMJ Open 2018, 8(5):e021080; doi: 10.1136/bmjopen-2017-021080.

35. Hammond D, Reid JL, Cole AG, Leatherdale ST. Electronic cigarette use and smoking initiation among youth: A longitudinal cohort study. CMAJ 2017, 189(43):E1328-1336; doi: 10.1503/cmaj.161002.

36. Barrington-Trimis JL, Kong G, Leventhal AM, Liu F, Mayer M, Cruz TB, Krishnan-Sarin S, McConnell R. E-cigarette use and subsequent smoking frequency among adolescents. Pediatrics 2018a, 142(6):e20180486; doi: 10.1542/peds.2018-0486.

37. Barrington-Trimis JL, Leventhal AM, Alonzo TA, Cruz TB, Urman R, Liu F, Pentz MA, Unger JB, McConnell R. Performance of cigarette susceptibility index among e-cigarette and hookah users. Drug Alcohol Depend 2018b, 183:43-50; doi: 10.1016/j.drugalcdep.2017.08.005.

38. Barrington-Trimis JL, Urman R, Berhane K, Unger JB, Cruz TB, Pentz MA, Samet JM, Leventhal AM, McConnell R. E-cigarettes and future cigarette use. Pediatrics 2016, 138(1):e20160379; doi: 10.1542/peds.2016-0379.

39. Berry KM, Fetterman JL, Benjamin EJ, Bhatnagar A, Barrington-Trimis JL, Leventhal AM, Stokes A. Association of electronic cigarette use with subsequent initiation of tobacco cigarettes in US youths. JAMA Netw Open 2019, 2(2):e187794; doi: 10.1001/jamanetworkopen.2018.7794.

40. Watkins SL, Glantz SA, Chaffee BW. Association of noncigarette tobacco product use with future cigarette smoking among youth in the Population Assessment of Tobacco and Health (PATH) Study, 2013-2015. JAMA Pediatr 2018, 172(2):181-187; doi: 10.1001/jamapediatrics.2017.4173.

41. Leventhal AM, Stone MD, Andrabi N, Barrington-Trimis J, Strong DR, Sussman S, Audrain-McGovern J. Association of e-cigarette vaping and progression to heavier patterns of cigarette smoking. JAMA 
2016, 316(18):1918-1920; doi: 10.1001/jama.2016.14649.

42. Lozano P, Barrientos-Gutierrez I, Arillo-Santillan E, Morello P, Mejia R, Sargent JD, Thrasher JF. A longitudinal study of electronic cigarette use and onset of conventional cigarette smoking and marijuana use among Mexican adolescents. Drug Alcohol Depend 2017, 180:427-430; doi:

10.1016/j.drugalcdep.2017.09.001.

43. Miech R, Patrick ME, O'Malley PM, Johnston LD. E-cigarette use as a predictor of cigarette smoking: results from a 1-year follow-up of a national sample of 12th grade students. Tob Control 2017, 26(e2):e106-111; doi: 10.1136/tobaccocontrol-2016-053291.

44. Spindle TR, Hiler MM, Cooke ME, Eissenberg T, Kendler KS, Dick DM. Electronic cigarette use and uptake of cigarette smoking: A longitudinal examination of U.S. college students. Addict Behav 2017, 67:66-72; doi: 10.1016/j.addbeh.2016.12.009.

45. Wills TA, Gibbons FX, Sargent JD, Schweitzer RJ. How is the effect of adolescent e-cigarette use on smoking onset mediated: A longitudinal analysis. Psychol Addict Behav 2016, 30(8):876-886; doi: 10.1037/adb0000213.

46. Wills TA, Sargent JD, Gibbons FX, Pagano I, Schweitzer R. E-cigarette use is differentially related to smoking onset among lower risk adolescents. Tob Control 2017a, 26(5):534-539; doi: 10.1136/tobaccocontrol-2016-053116.

47. Wills TA, Knight R, Sargent JD, Gibbons FX, Pagano I, Williams RJ. Longitudinal study of e-cigarette use and onset of cigarette smoking among high school students in Hawaii. Tob Control 2017b, 26(1):34-39; doi: 10.1136/tobaccocontrol-2015-052705.

48. Conner M, Grogan S, Simms-Ellis R, Flett K, Sykes-Muskett B, Cowap L, Lawton R, Armitage CJ, Meads D, Torgerson C et al. Do electronic cigarettes increase cigarette smoking in UK adolescents? Evidence from a 12-month prospective study. Tob Control 2018, 27(4):365-372; doi: 10.1136/tobaccocontrol-2016-053539.

49. East K, Hitchman SC, Bakolis I, Williams S, Cheeseman H, Arnott D, McNeill A. The association between smoking and electronic cigarette use in a cohort of young people. J Adolesc Health 2018, 62(5):539-547; doi: 10.1016/j.jadohealth.2017.11.301.

50. Morgenstern M, Nies A, Goecke M, Hanewinkel R. E-cigarettes and the use of conventional cigarettes. Dtsch Arztebl International2018, 115(14):243-248; doi: 10.3238/arztebl.2018.0243.

51. Treur JL, Rozema AD, Mathijssen JJP, van Oers H, Vink JM. E-cigarette and waterpipe use in two adolescent cohorts: Cross-sectional and longitudinal associations with conventional cigarette smoking. Eur J Epidemiol 2018, 33(3):323-334; doi: 10.1007/s10654-017-0345-9.

52. Best C, Haseen F, Currie D, Ozakinci G, MacKintosh AM, Stead M, Eadie D, MacGregor A, Pearce J, Amos $\mathrm{A}$ et al. Relationship between trying an electronic cigarette and subsequent cigarette experimentation in Scottish adolescents: A cohort study. Tob Control 2018, 27(4):373-378; doi: 10.1136/tobaccocontrol-2017-053691.

53. Kinnunen JM, Ollila H, Minkkinen J, Lindfors PL, Timberlake DS, Rimpelä AH. Nicotine matters in predicting subsequent smoking after e-cigarette experimentation: A longitudinal study among 
Finnish adolescents. Drug Alcohol Depend 2019, 201:182-187; doi:

10.1016/j.drugalcdep.2019.04.019.

54. Singh T, Arrazola RA, Corey CG, Husten CG, Neff LJ, Homa DM, King BA. Tobacco use among middle and high school students: United States, 2011-2015. MMWR Morb Mortal Wkly Rep 2016, 65(14):361-367; doi: 10.15585/mmwr.mm6514a1.

55. European Monitoring Centre for Drugs and Drug Addiction. Handbook for surveys on drug use among the general population. EMCDDA project CT.99.EP.08 B. Lisbon: EMCDDA; 2002; 151pp. Available from: https://www.emcdda.europa.eu/html.cfm/index58052EN.html_en

56. Etter JF. Gateway effects and electronic cigarettes. Addiction 2018, 113(10):1776-1783; doi: 10.1111/add.13924.

57. Birge M, Duffy S, Miler JA, Hajek P. What proportion of people who try one cigarette become daily smokers? A meta-analysis of representative surveys. Nicotine Tob Res 2017, 20(12):1427-1433; doi: 10.1093/ntr/ntx243.

58. Peruga A, World Health Organization Regional Office for Europe. Electronic nicotine and non-nicotine delivery systems: a brief. Copenhagan: WHO Regional Office for Europe. ; 2020; 20pp. Available from: http://www.euro.who.int/en/health-topics/disease-

prevention/tobacco/publications/2020/electronic-nicotine-and-non-nicotine-delivery-systems-a-brief2020

59. Kandel ER, Kandel DB. A molecular basis for nicotine as a gateway drug. New Engl J Med 2014, 371(10):932-943; doi: 10.1056/NEJMsa1405092.

60. Rhee SH, Hewitt JK, Young SE, Corley RP, Crowley TJ, Stallings JC. Genetic and environmental influences on substance initiation, use, and problem use in adolescents. Arch Gen Psychiatry 2003, 60:1256-1264; doi: 10.1001/archpsyc.60.12.1256.

61. Kendler KS, Myers J, Prescott CA. Specificity of genetic and environmental risk factors for symptoms of cannabis, cocaine, alcohol, caffeine, and nicotine dependence. Arch Gen Psychiatry 2007, 64:1313-1320; doi: 10.1001/archpsyc.64.11.1313.

62. Vanyukov MM, Tarter RE, Kirillova GP, Kirisci L, Reynolds MD, Kreek MJ, Conway KP, Maher BS, lacono WG, Bierut $L$ et al. Common liability to addiction and "gateway hypothesis": Theoretical, empirical and evolutionary perspective. Drug Alcohol Depend 2012, 123 S3-S17; doi:

10.1016/j.drugalcdep.2011.12.018.

63. Palmer RHC, Young SE, Hopfer CJ, Corley RP, Stallings MC, Crowley TJ, Hewitt JK. Developmental epidemiology of drug use and abuse in adolescence and young adulthood: Evidence of generalized risk. Drug Alcohol Depend 2009, 102(1-3):78-87; doi: 10.1016/j.drugalcdep.2009.01.012.

64. Schneider S, Diehl K. Vaping as a catalyst for smoking? An initial model on the initiation of electronic cigarette use and the transition to tobacco smoking among adolescents. Nicotine Tob Res 2015, 18(5):647-653; doi: 10.1093/ntr/ntv193.

65. McCarthy A, Lee C, O'Brien D, Long J. Harms and benefits of e-cigarettes and heat-not-burn tobacco products: A literature map. Dublin, Ireland: Health Research Board; 2020; 461 pp. Available from: 
https://www.hrb.ie/publications/publication/harms-and-benefits-of-e-cigarettes-and-heat-not-burntobacco-products-a-literature-map/returnPage/1/

66. Global Burden of Disease 2015 Tobacco Collaborators. Smoking prevalence and attributable disease burden in 195 countries and territories, 1990-2015: a systematic analysis from the Global Burden of Disease Study 2015 [published correction appears in Lancet. 2017 Oct 7;390(10103):1644]. Lancet 2017, 389(10082):1885-1906; doi: 10.1016/S0140-6736(17)30819-X.

67. World Health Organization. WHO Report on the Global Tobacco Control Epidemic, 2019: Offer help to quit tobacco use. Geneva: World Health Organization; 2019. Available from:

https://apps.who.int/iris/bitstream/handle/10665/326043/9789241516204-eng.pdf?ua=1

68. Thomson G, Edwards R, Wilson Nea. What are the elements of the tobacco endgame? Tob Control 2012, 21:293-295; doi: 10.1136/tc.2010.040881.

69. Malone RE. The race to a tobacco endgame Tob Control 2016, 25:607-608; doi: 10.1136/tobaccocontrol-2016-053466.

70. Perrine CG, Pickens CM, Boehmer TK. Characteristics of a multistate outbreak of lung injury associated with e-cigarette use, or vaping - United States, 2019. MMWR Morb Mortal Wkly Rep 2019, 68:860-864.

71. Abrams DB, Glasser AM, Pearson JL, Villanti AC, Collins LK, Niaura RS. Harm minimization and tobacco control: Reframing societal views of nicotine use to rapidly save lives. Annu Rev Public Health 2018, 39:193-213; doi: 10.1146/annurev-publhealth-040617-013849.

72. Glantz SA, Bareham DW. E-cigarettes: use, effects on smoking, risks, and policy implications. Annu Rev Public Health 2018, 39:215-235; doi: 10.1146/annurev-publhealth-040617-013757.

73. Fairchild AL, Bayer R, Colgrove J. The renormalization of smoking? E-cigarettes and the tobacco "endgame". New Engl J Med 2014 370(4):293-295; doi: 10.1056/NEJMp1313940.

74. Fairchild AL, Bayer R. Public health. Smoke and fire over e-cigarettes. Science 2015, 347(6220):375376; doi: 10.1126/science.1260761.

75. Fairchild AL, Bayer R, Lee JS. The e-cigarette debate: what counts as evidence? Am J Public Health 2019, 109(7):1000-1006; doi: 10.2105/AJPH.2019.305107.

76. National Academies of Sciences, Engineering, Medicine. Public health consequences of ecigarettes. Washington DC, USA: The National Academies Press; 2018; 774pp. Available from: https://dx.doi.org/10.17226/24952

77. Scientific Committee on Health, Environmental and Emerging Risks (SCHEER),. Request for a scientific opinion on electronic cigarettes. European Commission,; 2020: 2pp. Available from: https://ec.europa.eu/health/sites/health/files/scientific_committees/scheer/docs/scheer_q_013.pdf

78. Quigley JM, Kennelly H, Lee C, O’Brien D, Williams M, McCarthy A, Long J. Electronic cigarettes and smoking cessation: An evidence review. Dublin, Ireland: Health Research Board; 2020. Available from: https://www.hrb.ie/publications/publication/electronic-cigarette-and-smoking-cessation-anevidence-review/returnPage/ $1 /$ 
79. Pisinger C, Døssing M. A systematic review of health effects of electronic cigarettes. Prev Med 2014, 69:248-260; doi: 10.1016/j.ypmed.2014.10.009.

80. Canadian Agency for Drugs and Technologies in Health (CADTH). Electronic cigarettes for the reduction or cessation of smoking: Clinical utility, safety, and guidelines. Ottawa, Canada: Canadian Agency for Drugs and Technologies in Health (CADTH);; 2017. Available from:

https://cadth.ca/electronic-cigarettes-reduction-or-cessation-smoking-clinical-utility-safety-andguidelines-0

81. Byrne S, Brindal E, Williams G, Anastasiou K, Tonkin A, Battams S, Riley MD. E-cigarettes, smoking and health: A literature review update. Australia: Commonwealth Scientific and Industrial Research Organisation (CSIRO) 2018; 394pp. Available from:

https://www.csiro.au/en/Research/BF/Areas/Nutrition-and-health/Public-health-and-wellbeing/Casestudies/E-cigarettes-report

82. Bals R, Boyd J, Esposito S, Foronjy R, Hiemstra PS, Jimenez-Ruiz CA, Katsaounou P, Lindberg A, Metz C, Schober W et al. Electronic cigarettes: A task force report from the European Respiratory Society. Eur Resp J 2019, 53(2):1801151; doi: 10.1183/13993003.01151-2018.

83. Greenhalgh T, Malterud K. Systematic reviews for policymaking: Muddling through. Am J Public Health 2017, 107(1):97-99; doi: 10.2105/AJPH.2016.303557.

\section{Figures}

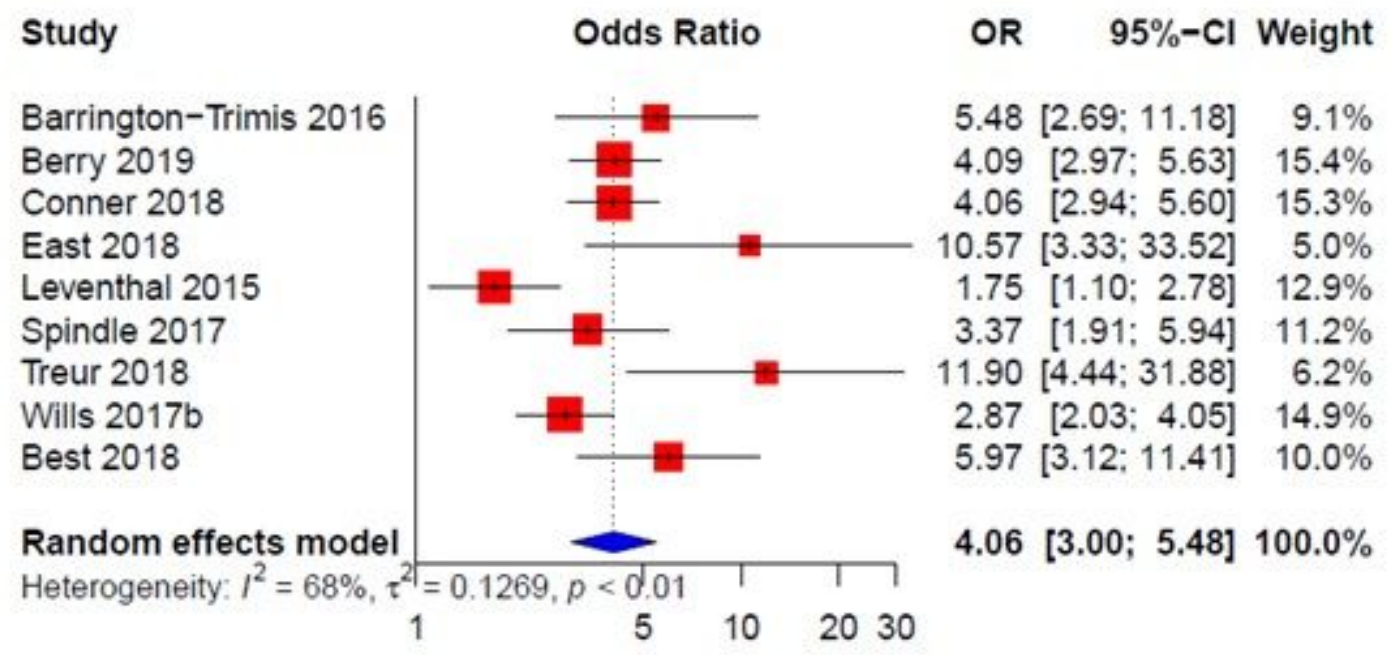

Figure 1

Meta-analysis results, using primary study adjusted odds ratio (AOR), for association between ever ecigarette use and subsequent smoking 


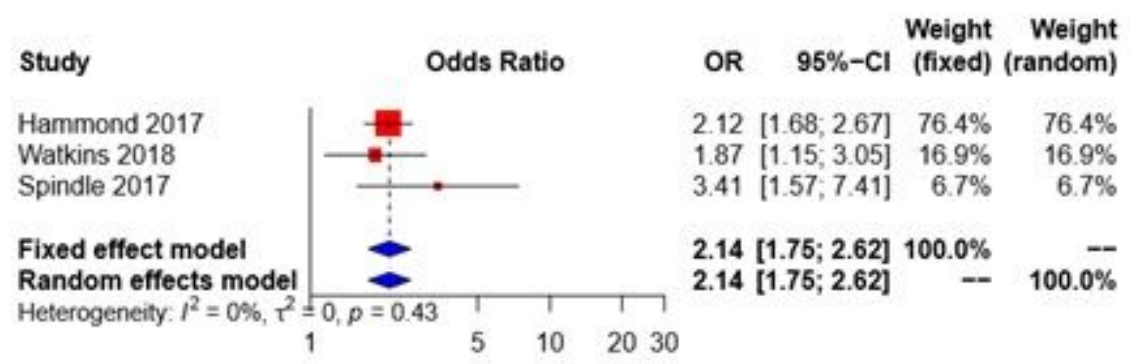

Figure 2

Meta-analysis results, using primary study adjusted odds ratio (AOR), for association between past 30day e-cigarette use and subsequent smoking

\section{Supplementary Files}

This is a list of supplementary files associated with this preprint. Click to download.

- Supplementaryappendices.ods 